\title{
Stress Corrosion Cracking of SUS 631 Stainless Steel Deformed at High Strain Rate*
}

\author{
By Hitoshi UCHIDA,** Keiji KOTERAZAWA** and Iwao YAMADA**
}

\section{Synopsis}

The effect of cold working on stress corrosion cracking (SCC) susceptibility of semiaustenitic precipitation-hardening stainless steel has been investigated in the present study. The specimens, prepared from $A$ treated SUS 631 stainless steel sheets containing delta ferrite, were prestrained at low or high strain rate and successively subjected to THtreatment. The SCC susceptibility of these specimens was estimated in boiling $\mathrm{MgCl}_{2}$ solution under the constant applied stress.

The cold working gives a remarkable effect not only for the mechanical properties but for the SCC susceptibility of A-and TH-treated specimens. Namely, the strength of TH-treated specimens decreased with increasing prestrain, and the strength level of these specimens prestrained at high strain rate was larger than those at low strain rate. But, the abovementioned behavior of TH-treated specimens was the very reverse to that of A-treated specimens. While, the SCC susceptibility of A- and THtreated specimens decreased with increasing prestrain, and its susceptibility of these specimens prestrained at high strain rate was larger than those at low strain rate.

On the basis of the results obtained above, the effects of prestrain and strain rate on the SCG susceptibility of SUS 631 stainless steel were discussed.

\section{Introduction}

Precipitation-hardening stainless steel, high-strength steel in itself, is representative of the alloy that preserves its corrosion resistance as so-called "stainless steel" and that increases its strength and hardness through a combination of martensitic transformation and precipitation-hardening, and a few types have developed.1) Generally, it is known that semiaustenitic SUS 631 stainless steel is superior in the cold working property and practically hardened by double heat treatment after cold working.

While, a few papers ${ }^{2-6)}$ on stress corrosion cracking (SCC) of precipitation-hardening stainless steels have mainly discussed the effect of heat treatment conditions on SCG susceptibility in various corrosive environments. For the sake of clarifying that these steels can be more widely used or not as SGC-resistant steel, it is important to investigate the effect of cold working conditions on SCG susceptibility. It is seemed, however, that such a paper has not been published to date.

On SUS 631 stainless steel prestrained at low or high strain rate and successively performed double heat treatment, the effects of prestrain and strain rate on SCG susceptibility have been investigated in the present study.

\section{Experimental Procedure}

\section{Material and Specimen Preparation}

The commercial SUS 631 stainless steel (solution annealed, hereinafter referred to as " $A$ ") was used in the present study. The chemical compositions and the mechanical properties are shown in Tables 1 and 2 , respectively. In the case of as-received material, the two-phase structure containing austenite of matrix and delta ferrite, laminated, parallel to rolling direction is observed as shown in Photo. 1. The specimens (Fig. 1(a)) used for cold working (hereinafter referred to as " $\mathrm{W}$ ") were machined from asreceived material with their tensile axis parallel to rolling direction. At room temperature $\left(20^{\circ} \sim 22^{\circ} \mathrm{C}\right)$, the prestrain of these specimens was given at the strain rate of $1.7 \times 10^{-3}$ and $6 \times 10 \mathrm{sec}^{-1}$ (hereinafter referred to as suffix " $S$ " and " $D$ ") by Instron type and explosive type tensile testing machine, ${ }^{7)}$ respectively. After being subjected to the double heat treatment mentioned below, these specimens were machined for SCG specimens as shown in Fig. 1(b). The surface finishing process of SCG specimens was similar to the previous paper ${ }^{8)}$ such as emery polishing, electrolytic polishing, degreasing and mixed acids immersing.

\section{Heat Treatment}

As-received material is semiaustenitic precipitation-hardening stainless steel. In this case, the double

Table 2. Mechanical properties of as-received material.

\begin{tabular}{c|cccc}
\hline $\begin{array}{c}\text { Heat } \\
\text { treatment }\end{array}$ & $\begin{array}{c}\text { Yield } \\
\text { strength* } \\
\left(\mathrm{kg} / \mathrm{mm}^{2}\right)\end{array}$ & $\begin{array}{c}\text { Tensile } \\
\text { strength } \\
\left(\mathrm{kg} / \mathrm{mm}^{2}\right)\end{array}$ & $\begin{array}{c}\text { Elongation } \\
(\%)\end{array}$ & $\begin{array}{c}\text { Hardness** } \\
(\text { D.P.N.) }\end{array}$ \\
\hline $\mathrm{A}$ & 36.7 & 79.7 & 44.8 & 180.3 \\
\hline
\end{tabular}

$* 0.2 \%$ off-set

** load of $500 \mathrm{~g}$

Table 1. Chemical compositions of as-received material. (wt $\%$ )

\begin{tabular}{c|ccccccccccc}
\hline Material & $\mathrm{C}$ & $\mathrm{Si}$ & $\mathrm{Mn}$ & $\mathrm{P}$ & $\mathrm{S}$ & $\mathrm{Ni}$ & $\mathrm{Cr}$ & $\mathrm{Mo}$ & $\mathrm{Cu}$ & $\mathrm{Al}$ \\
\hline SUS 631 & 0.07 & 0.48 & 0.72 & 0.029 & 0.004 & 7.06 & 17.13 & 0.17 & 0.12 & 1.06 \\
\hline
\end{tabular}

* Originally published in Corrosion Engineering (Boshoku Gijutsu), 28 (1979), 386, in Japanese. English version received February 12, 1980.

** Himeji Institute of Technology, Shosha, Himeji 671-22. 


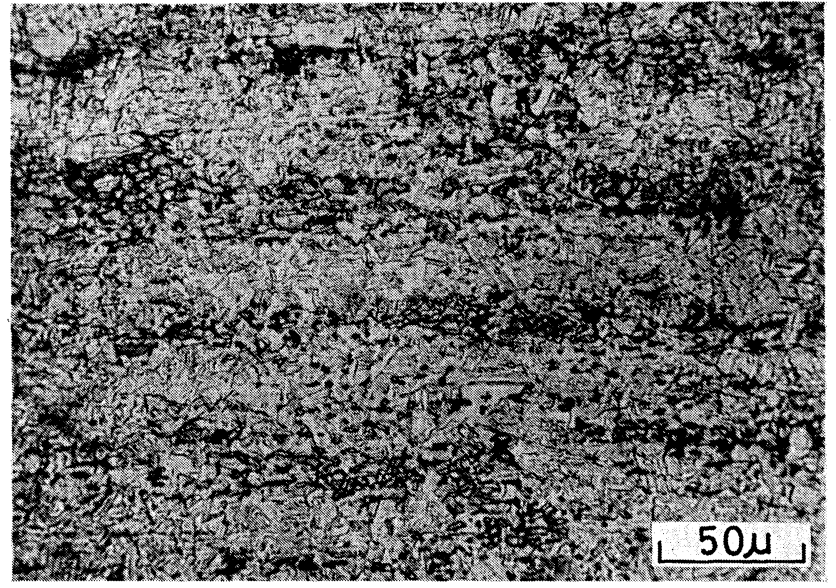

_- Rolling direction -

Photo. 1. Microstructure of as-received material.

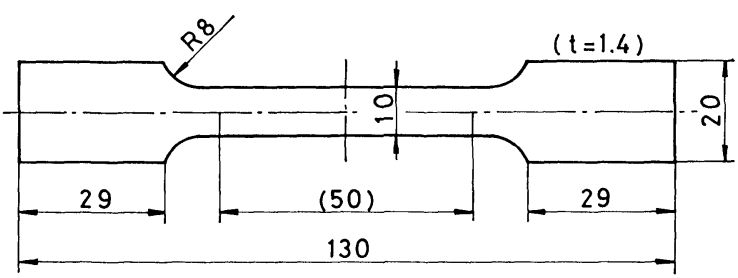

(a)

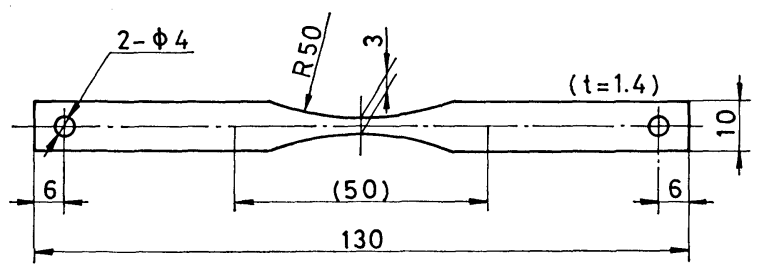

(b)

(a) for prestraining and tensile testing

(b) for SCG testing

Fig. 1. Dimension of specimens. (mm)

heat treatment of TH 1050 (JIS G 4305 (1972), hereinafter referred to as " $\mathrm{TH}$ ") is in general use for precipitation-hardening treatment. ${ }^{1)}$ Namely, the transformation of austenite to martensite was induced by $\mathrm{T}$-treatment $\left(760^{\circ} \mathrm{C} \times 1.5 \mathrm{hr}\right.$, ice water cooled), and its martensite was precipitation-hardened by $\mathrm{H}$ treatment $\left(565^{\circ} \mathrm{C} \times 1.5 \mathrm{hr}\right.$, air cooled), successively.

\section{SCC Test}

The SCG tests in boiling 35\% (adjusted to $\mathrm{pH} 3$ at room temperature by hydrochloric acid) and $42 \%$ $\mathrm{MgCl}_{2}$ solution were carried out by the constant tensile loading apparatus. ${ }^{9)}$ The specimens used in SGG (or tensile) tests were of $\mathrm{A}$ series $\left(\mathrm{A}, \mathrm{A}-\mathrm{W}_{\mathrm{S}}\right.$ and $\mathrm{A}$ $\mathrm{W}_{\mathrm{D}}$ ) and $\mathrm{TH}$ series (A-TH, A-W $\mathrm{S}^{-} \mathrm{TH}$ and $\mathrm{A}-\mathrm{W}_{\mathrm{D}^{-}}$ $\mathrm{TH}$ ), and these symbols were classified according to the process of specimen preparations in the present paper.

\section{Experimental Results}

\section{Tensile Test}

The results obtained through tensile test $(1.7 \times$

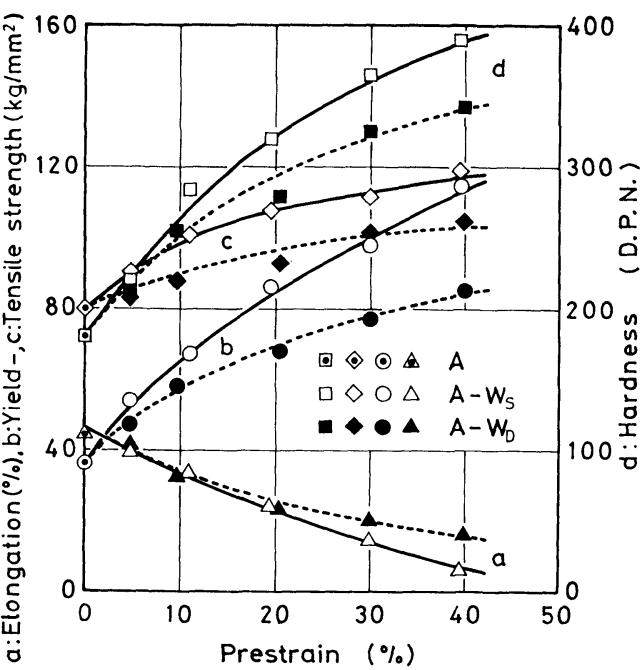

Fig. 2. Effects of prestrain and strain rate on yield strength, tensile strength, elongation and hardness of A series specimens.

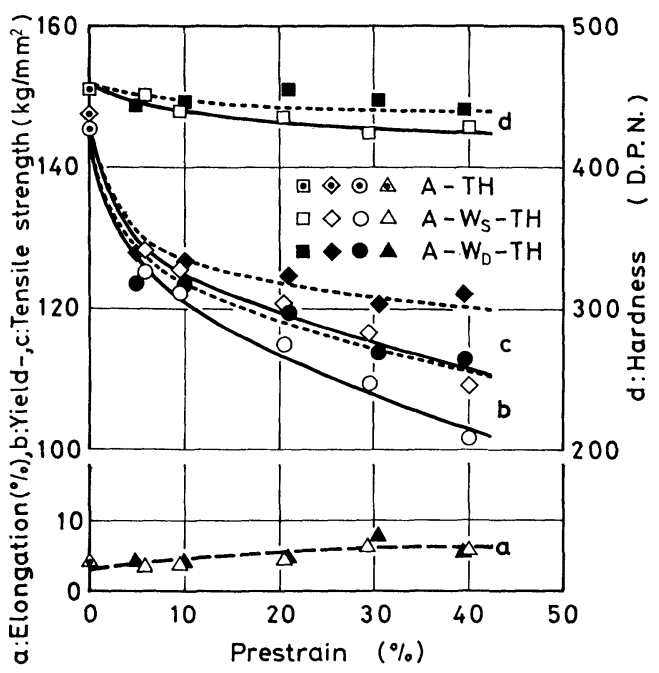

Fig. 3. Effects of prestrain and strain rate on yield strength, tensile strength, elongation and hardness of $\mathrm{TH}$ series specimens.

$10^{-3} \mathrm{sec}^{-1}$, room temperature) are shown in Fig. 2. At any prestrain value in Fig. 2, the yield strength, tensile strength and hardness of $A-W_{D}$ specimens are smaller than those of $\mathrm{A}-\mathrm{W}_{\mathrm{S}}$ specimens. While, the elongation of $A-W_{D}$ specimens is conversely larger than that of $\mathrm{A}-\mathrm{W}_{\mathrm{S}}$ specimens.

In the same way as Fig. 2, the results of $\mathrm{TH}$ series specimens are shown in Fig. 3. The strength of TH series specimens decreases with increasing prestrain. Furthermore, at any prestrain value in Fig. 3, the yield strength, tensile strength and hardness of $A-W_{D^{-}}$ TH specimens are larger than those of $\mathrm{A}-\mathrm{W}_{\mathrm{s}}-\mathrm{TH}$ specimens; however, both elongations are a negligible difference. As mentioned above, the behavior of $\mathrm{TH}$ series specimens is the very reverse to that of $\mathrm{A}$ series specimens.

\section{SCC Test}

The results obtained through SCG test of A and A-TH specimens are shown in Fig. 4. The SCC 
threshold stress of A-TH specimens is larger than that of A specimens. At any applied stress level over the SCG threshold stress of A-TH specimens, however, A-TH specimens fracture at shorter time than in the case of A specimens. While, on estimating the SCG susceptibility of both specimens from the relation between time to fracture and ratio of applied stress/ yield strength, it is found that the SCC susceptibility of A-TH specimens is larger than that of A specimens at any ratio of applied stress/yield strength.

The results obtained through SCG test of A and TH series specimens are shown in Fig. 5. On the whole, the time to fracture of any specimen depends on the concentration of $\mathrm{MgCl}_{2}$ solution, and increases with increasing prestrain except that $40 \%$ prestrained A-W $W_{\mathrm{S}}$ specimens fracture at extremely short time. Furthermore, at any prestrain value in Fig. 5, the

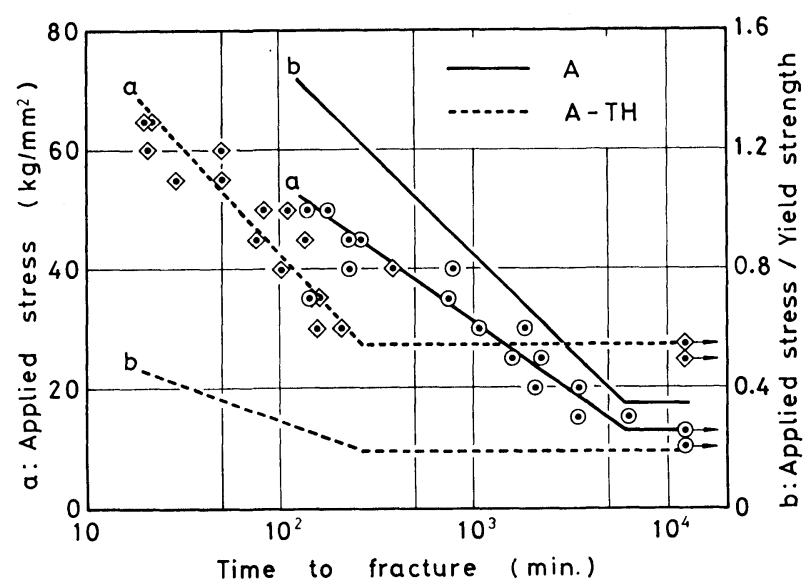

Fig. 4. Effect of applied stress on time to fracture of A and $\mathrm{A}-\mathrm{TH}$ specimens in boiling $35 \% \mathrm{MgCl}_{2}$ solution.

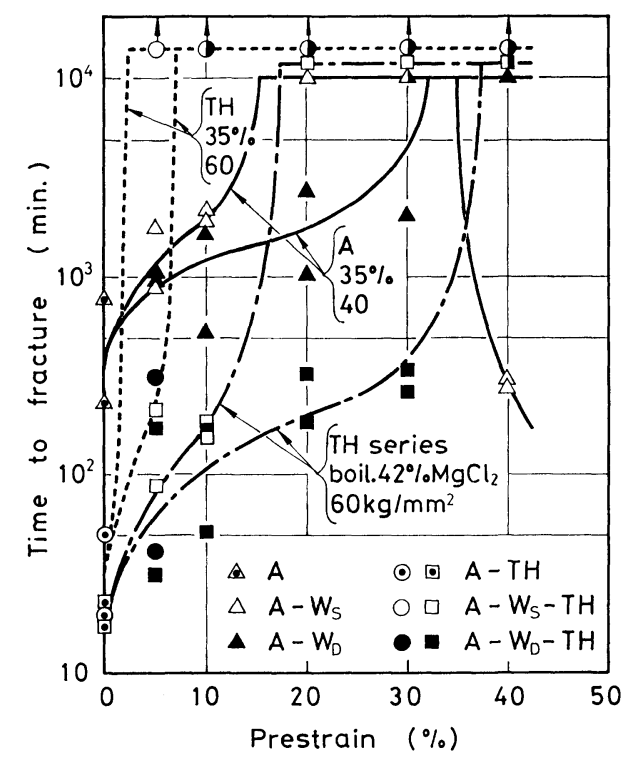

Fig. 5. Effects of prestrain and strain rate on time to fracture of $\mathrm{A}$ and $\mathrm{TH}$ series specimens in boiling 35\% and $42 \% \mathrm{MgCl}_{2}$ solution.
SCG susceptibility of both $A-W_{D}$ and $A-W_{D}-T H$ specimens is larger than that of both $A-W_{S}$ and $A-$ $\mathrm{W}_{\mathrm{S}}-\mathrm{TH}$ specimens.

\section{Observation of $S C C$ Fracture Surface}

Since SCC fracture surface morphology mainly depends on heat treatment conditions, its morphology of $\mathrm{A}$ and $\mathrm{A}-\mathrm{TH}$ specimens is shown in Photo. 2 as an example. The SCG of A specimen is initiated and propagated by mixing of intergranular and transgranular fracture (Photos. 2(a) and (b)), and its mechanical fracture surface shows the ductile pattern with dimple (Photo. 2(c)). While, the SCG of A-TH specimen is initiated at transgranular and changed to mixing fracture mode (Photos. 2(d) and (e)), and its mechanical fracture surface shows the brittle pattern with quasi-cleavage (Photo. 2(f)).

\section{Discussion}

As mentioned above, it was found that the cold working gave a remarkable effect not only for the mechanical properties but for the SCG susceptibility.

Hereinafter, the effects of prestrain and strain rate on the mechanical properties and SCG susceptibility of $\mathrm{TH}$ series specimens are discussed in comparison with A series specimens.

\section{Mechanical Properties}

As shown in Fig. 2, the mechanical properties of A series specimens are similar to those of SUS 301 stainless steel reported in the previous paper. ${ }^{8)}$ In the case of such steels with metastable austenite, it is expected that the strain rate in prestraining has a great influence not only on the strain-induced $\alpha^{\prime}$ martensitic transformation ${ }^{8,9)}$ but on the age-hardening.

The stress-strain curves of A specimens obtained through tensile test (room temperature) are shown in Fig. 6 as a function of strain rate. In this case, the yield strength increases with increasing strain rate, and this fact is mainly caused by "dynamic effect ".* While, the work hardening rate and consequently the flow stress level conversely decrease with increasing strain rate. This fact is caused by the following: The longer loading time of tensile stress is, the more age-hardening progresses. Consequently, it is seemed that the age-hardening in prestraining, as mentioned above, affects the mechanical properties of $\mathrm{A}$ series specimens.

Generally, as-received SUS 631 stainless steel used in the present study is semiaustenitic structure. By T-treatment, $\mathrm{Cr}$-carbides are precipitated at grain boundaries and then $M_{d}$ point is rised above room temperature. Consequently, the transformation of austenite to martensite is induced during cooling. Successively, by $\mathrm{H}$-treatment, $\mathrm{Ni}-\mathrm{Al}$ compounds are precipitated into its martensite, and consequently the precipitation-hardening progresses more remarkably. ${ }^{10)}$ As shown in Fig. 3, however, the precipitation-hardening of $\mathrm{TH}$ series specimens shows a com-

\footnotetext{
* Generally, the effect of strain rate on stress-strain curve includes both "dynamic effect" based on the change of only strain rate and

"structural effect" based on the change of structure caused by strain rate."
} 

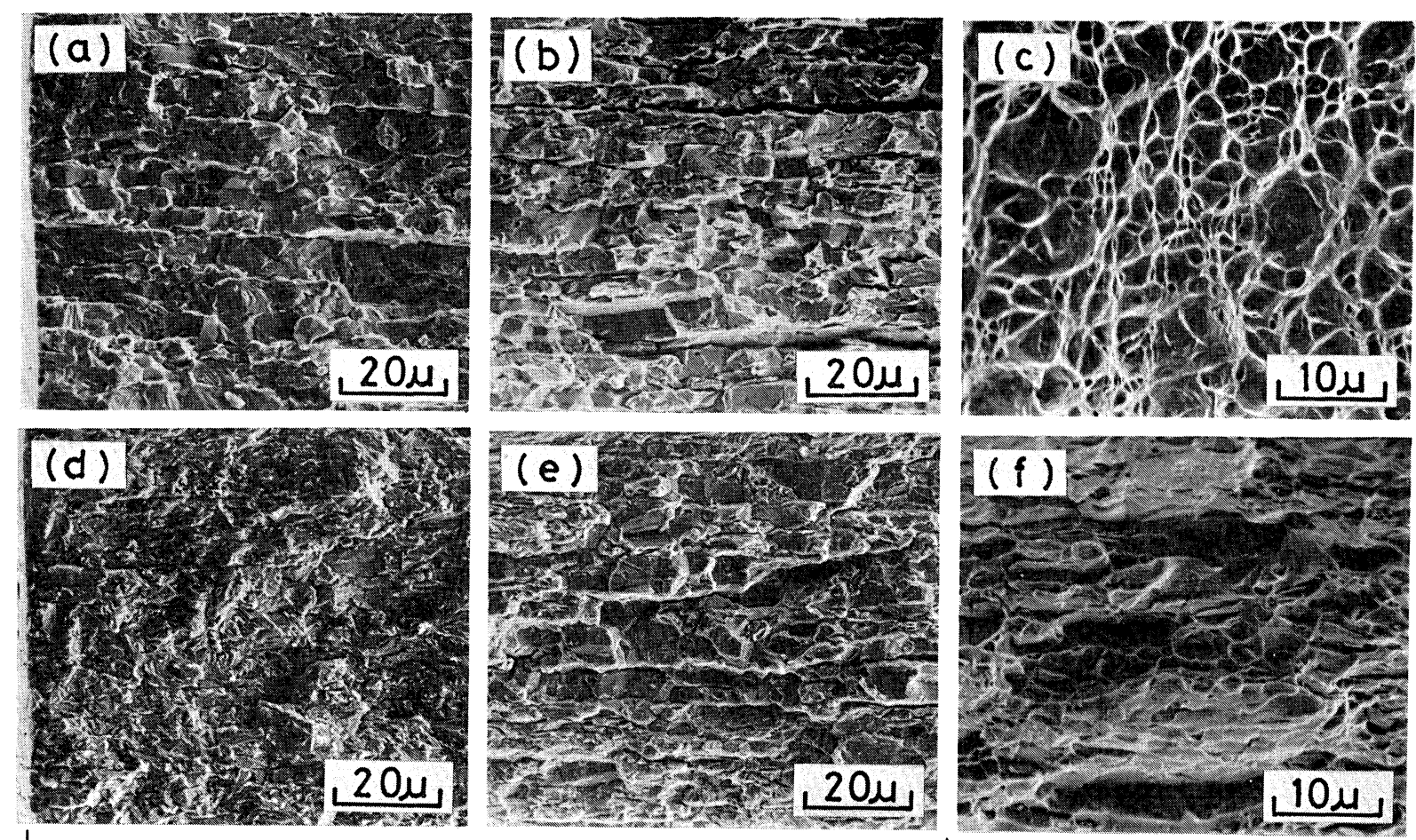

$\mathrm{SCC}$

Mechanical

\section{Initiated}

(a), (b), (c): A specimen, $40 \mathrm{~kg} / \mathrm{mm}^{2}$ applied

(d), (e), (f): A-TH specimen, $60 \mathrm{~kg} / \mathrm{mm}^{2}$ applied

Photo. 2. Effect of heat treatment conditions on SCG fracture surface morphology of A and A-TH specimens in boiling $35 \% \mathrm{MgCl}_{2}$ solution.

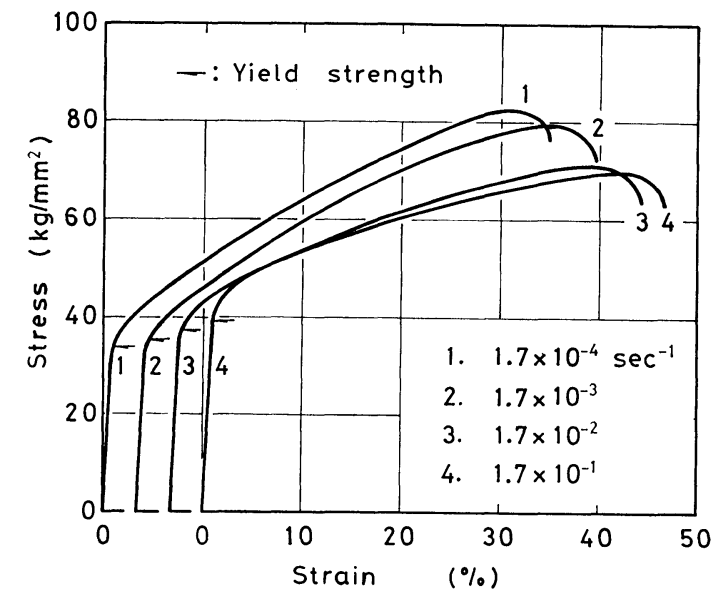

Fig. 6. Effect of strain rate on stress-strain curves of A specimens.

plicated behavior. Particularly, the strength of TH series specimens is different from that of A series specimens in point of the following:

(1) The strength of TH series specimens decreases with increasing prestrain.

(2) At any prestrain value, the strength level of $\mathrm{A}-\mathrm{W}_{\mathrm{D}}-\mathrm{TH}$ specimens is larger than that of $\mathrm{A}-\mathrm{W}_{\mathrm{S}}-\mathrm{TH}$ specimens.

As for the cause of (1) and (2) mentioned above, reverse transformation of martensite to austenite, grain coarsening, and so on during double heat treatment are considered. ${ }^{11-13)}$ In the present paper, the authors have paid attention to the reverse transforma-

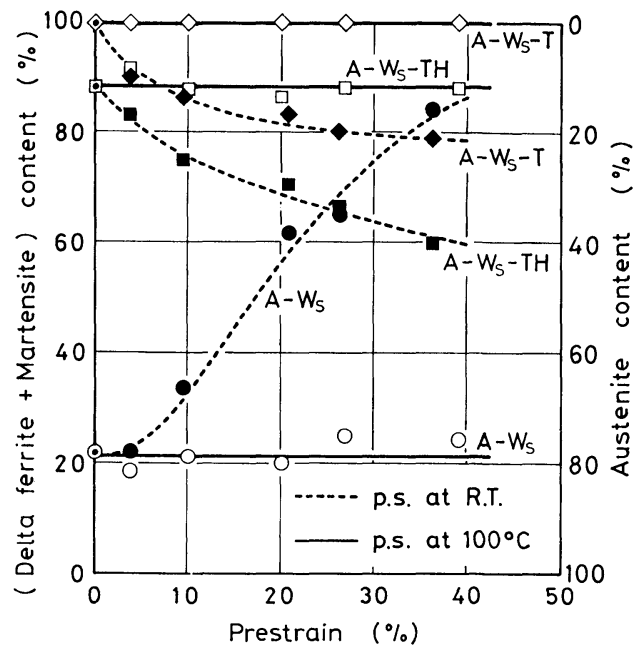

Fig. 7. Effects of prestrain, prestraining temperature and heat treatment conditions on delta ferrite, martensite and austenite content of $\mathrm{A}-\mathrm{W}_{\mathrm{S}}, \mathrm{A}-\mathrm{W}_{\mathrm{S}^{-}} \mathrm{T}$ and $\mathrm{A}-\mathrm{W}_{\mathrm{S}^{-}}$ TH specimens (strain-induced $\alpha^{\prime}$ martensite: included in " martensite content").

tion of strain-induced $\alpha^{\prime}$ martensite to austenite. ${ }^{14)}$ Then, the delta ferrite, martensite and austenite content obtained through X-ray diffraction method are shown in Fig. 7 as a function of heat treatment condition. In the case of $\mathrm{A}-\mathrm{W}_{\mathrm{S}}$ specimens prestrained at $100^{\circ} \mathrm{C}$ considered as the vicinity of $M_{d}$ point, austenite hardly transforms to strain-induced $\alpha^{\prime}$ martensite during prestraining, and each of these specimens always 
contains about $22 \%$ delta ferrite. ${ }^{*}$ Then, on the successive T-treated specimens, i.e., A-W $\mathrm{W}_{\mathrm{s}}-\mathrm{T}$ specimens, all retaining austenite of $\mathrm{A}-\mathrm{W}_{\mathrm{S}}$ specimens transforms to martensite during T-treatment. Furthermore, on the successive $\mathrm{H}$-treated specimens, i.e., $\mathrm{A}-\mathrm{W}_{\mathrm{S}}-\mathrm{TH}$ specimens, a part of martensite reversely transforms to austenite during $\mathrm{H}$-treatment, and its austenite content shows the constant value independent of prestrain. While, in the case of $\mathrm{A}-\mathrm{W}_{\mathrm{S}}$ specimens prestrained at room temperature, the strain-induced $\alpha^{\prime}$ martensite content increases with increasing prestrain. The more strain-induced $\alpha^{\prime}$ martensite content (or prestrain) of these specimens increases, the more reverse transformed austenite content of successive $\mathrm{T}$ treated specimens, i.e., A- $\mathrm{W}_{\mathrm{s}^{-}} \mathrm{T}$ specimens, increases. Furthermore, on the successive H-treated specimens, i.e., $\mathrm{A}-\mathrm{W}_{\mathrm{s}} \mathrm{TH}$ specimens, the degree of its reverse transformation enlarges still more.

As shown in Fig. 7, with increasing the prestrain given at room temperature, the reverse transformation of strain-induced $\alpha^{\prime}$ martensite to austenite occurs easily, and consequently the strength decreases. It is seemed that this fact has an effect on the behavior of (1) mentioned above. Furthermore, in the case of specimens prestrained at room temperature, since the strain-induced $\alpha^{\prime}$ martensite content depends on not only prestrain but strain rate, ${ }^{8,9)}$ it is expected that the reverse transformed austenite content of successive double heat treated specimens changes as follows: In the case of high strain rate prestraining, the temperature rise of specimen itself is larger, and consequently the strain-induced $\alpha^{\prime}$ martensite content is smaller, than in the case of low strain rate prestraining. Consequently, the reverse transformed austenite content of $\mathrm{A}-\mathrm{W}_{\mathrm{S}}-\mathrm{TH}$ specimens is larger than that of $\mathrm{A}-\mathrm{W}_{\mathrm{D}^{-}}$ TH specimens. It is seemed that this fact has an effect on the behavior of (2) mentioned above.

\section{SCG Susceptibility}

As shown in Fig. 4, the SCG threshold stress of A specimens is similar to that of SUS 301 stainless steel, ${ }^{8}$ while its stress of A-TH specimens increases more remarkably in comparison with A specimens. Since SUS 631 stainless steel used in the present study is generally used under a state of martensitic structure, the SCG susceptibility of this case is considered to be similar to that of martensitic stainless steel.

On estimating the SGC susceptibility with the ratio of applied stress/yield strength, however, it was shown that its susceptibility of A-TH specimens was larger than that of A specimens. The tensile surface morphology of A specimen is shown in Photo. 3 as an example. In the case of A specimens, the remarkable dissolution of delta ferrite during SCC testing is observed as compared with A-TH specimens. It is expected that the SCC behavior of A specimens with two-phase structure containing austenite of matrix and delta ferrite is similar to that of so-called "two- phase stainless steel". Generally, it is noted that the effective factors on the SGG susceptibility of twophase stainless steel scattered ferritic phase in austenitic phase of matrix are given as follows: (1) Since ferritic phase has more difficulty in deforming than austenitic phase, mechanically, the propagation of crack is prevented by ferritic phase, i.e., "keying effect". While, (2) since the corrosion potential of ferritic phase is less noble than that of austenitic phase, electrochemically, the propagation of crack is prevented by cathodic protection. ${ }^{15)}$ On conjecturing the dissolution of delta ferrite as shown in Photo. 3, it is seemed that the difference of SCG susceptibility between $\mathrm{A}$ and $\mathrm{A}-\mathrm{TH}$ specimens is under the influence of not only the change of structure based on double heat treatment but the factor of (2) mentioned above.

The effects of prestrain and strain rate on the SCG susceptibility of $\mathrm{A}$ and $\mathrm{TH}$ series specimens were shown in Fig. 5. In the case of A series specimens, not only the mechanical properties but the SCG susceptibility show a behavior similar to those of SUS 301 stainless steel reported in the previous paper. ${ }^{8)}$ It demonstrates that the SCG susceptibility of metastable austenitic stainless steel decreases with increasing prestrain and consequently with increasing strain-induced $\alpha^{\prime}$ martensite content. In too much strain-induced $\alpha^{\prime}$ martensite by prestraining, however,
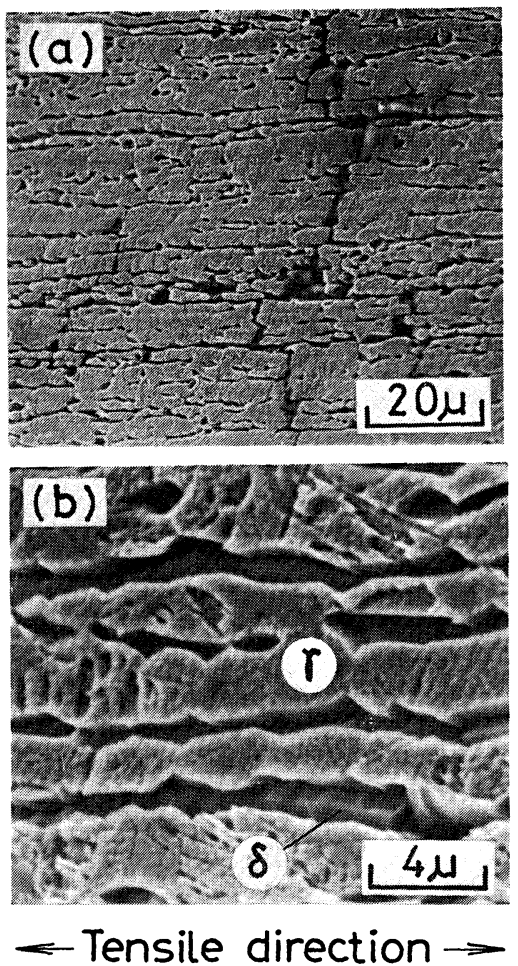

(a) outside view

(b) dissolution of delta ferrite $(\gamma$ : austenite, $\delta$ : delta ferrite)

Photo. 3. Tensile surface morphology of A specimen exposed to boiling $35 \% \mathrm{MgCl}_{2}$ solution during $\mathrm{SCC}$ testing.

* The effect of heat treatment conditions on each content of delta ferrite, martensite and austenite in $17 \mathrm{Cr}-7 \mathrm{Ni}-1 \mathrm{Al}$ alloy has been investigated by G. Krauss et al. ${ }^{11)}$ It is reported that the delta ferrite content, independent of heat treatment conditions, shows the constant value. 
its susceptibility increases reversely, i.e., as $40 \%$ prestrained $\mathrm{A}-\mathrm{W}_{\mathrm{S}}$ specimens fractured at extremely short time in the present study. On the basis of these results, it is noted that strain-induced $\alpha^{\prime}$ martensite has different effect on SCG susceptibility between in a large and small amount of its martensite.* Consequently, it is implied that the difference in SCC susceptibility of A series specimens as a function of prestrain and strain rate is mainly caused by the degree of strain-induced $\alpha^{\prime}$ martensitic transformation, and partially of age-hardening besides. While, in the case of TH series specimens, it is seemed that the electrochemical effect of two-phase structure, as discussed on A specimens, due to the reverse transformation slightly relates to the SCC susceptibility. In the present paper, however, the authors have paid attention to the following: The strength of $\mathrm{TH}$ series specimens decreases with increasing prestrain, and the strength level of $\mathrm{A}-\mathrm{W}_{\mathrm{D}}-\mathrm{TH}$ specimens is larger than that of $\mathrm{A}-\mathrm{W}_{\mathrm{s}}-\mathrm{TH}$ specimens. On the contrary, the SCG susceptibility of $A-W_{D}-T H$ specimens is larger than that of $\mathrm{A}-\mathrm{W}_{\mathrm{s}}-\mathrm{TH}$ specimens, and either of its susceptibility decreases with increasing prestrain. This fact indicates that it is difficult to estimate the SCG susceptibility of prestrained and successive double heat treated specimens, TH series specimens, with the dimension of strength level.

Generally, it is said that, since the solubility of hydrogen in ferritic and martensitic structure is small and then the diffusivity of that is large, the hydrogen embrittlement depends on mechanical properties, i.e., larger the tensile strength and hardness, it occurs easily. ${ }^{16)}$ D. G. Vreeland ${ }^{4)}$ has investigated the successful cathodic protection of precipitation-hardening stainless steels exposed to seawater, consequently the required cathodic potential range insusceptible to pitting, crevice corrosion and hydrogen embrittlement was clarified. While, C. T. Fujii ${ }^{6}$ ) has indicated that the SGC susceptibility of 17-7PH steel increases with increasing cathodic potential, and futhermore put emphasis on the role of hydrogen in SCG mechanism. As clarified in the present study, the SCG susceptibility of $\mathrm{TH}$ series specimens with martensitic structure decreases with increasing prestrain and consequently decreasing strength. On the basis of this fact, it is likely seemed that the SCC of TH series specimens is mainly caused by hydrogen embrittlement, now under investigation in details.

\section{Conclusion}

The effects of prestrain and strain rate on the SCG susceptibility of TH series specimens prepared from SUS 631 stainless steel were investigated in boiling $\mathrm{MgCl}_{2}$ solution, and the results were compared with those of A series specimens. The main results obtained are summarized as follows:
(1) The cold working gives a remarkable effect not only for the mechanical properties but for the SCG susceptibility of A and TH series specimens.

(2) The strength of $\mathrm{TH}$ series specimens decreases with increasing prestrain. The strength level of A$\mathrm{W}_{\mathrm{D}}-\mathrm{TH}$ specimens is larger than that of $\mathrm{A}-\mathrm{W}_{\mathrm{S}}-\mathrm{TH}$ specimens. The above-mentioned behavior is the very reverse to that of A series specimens.

(3) The SCC susceptibility of A and TH series specimens decreases with increasing prestrain. The SCG susceptibility of A- $\mathrm{W}_{\mathrm{D}}-\mathrm{TH}$ specimens is larger than that of $\mathrm{A}-\mathrm{W}_{\mathrm{S}}-\mathrm{TH}$ specimens.

(4) The SCG fracture surface morphology mainly depends on heat treatment conditions. The SCG of A series specimens is initiated and propagated in the mode of mixture of intergranular and transgranular fracture. The SCC of TH series specimens is initiated at transgranular and changed to mixing fracture mode.

\section{Acknowledgements}

The authors are pleased to acknowledge the support of Himeji Works, Nippon Kayaku Corp. and Hanshin Works, Kawasaki Steel Corp. Sincere appreciation is also due to Mr. M. Irie for his assistance to carry out the experiments.

\section{REFERENCES}

1) K. Ebato: Stainless Steels Handbook (Sutenresu-ko Binran), ed. by M. Hasegawa, Nikkan Kogyo Shinbunsha, Tokyo, (1976), 483.

2) R. A. Davis, G. A. Dreyer and W. G. Gallaugher: Corrosion, 20 (1964), 93.

3) M. Mizuno, S. Shimodaira, G. Ito, H. Atsumo, K. Yokota and S. Onodera: Bull. Japan Inst. Metals, 3 (1964), 622.

4) D. C. Vreeland: Mat. Protect. Perform., 9 (1970), 32.

5) C. S. Carter, D. G. Farwick, A. M. Ross and J. M. Uchida: Corrosion, 27 (1971), 190.

6) G. T. Fujii: Stress Corrosion-New Approaches, ed. by H. L. Craig, Jr., ASTM Special Tech. Publ., (1976), 213.

7) I. Yamada, T. Sugita and K. Koterazawa: J. Soc. Mat. Sci., Japan, 14 (1965), 192.

8) H. Uchida, K. Koterazawa and I. Yamada: Corrosion Engineering (Boshoku Gijutsu), 27 (1978), 63.

9) H. Uchida, K. Koterazawa and I. Yamada: Corrosion Engineering (Boshoku Gijutsu), 25 (1976), 543.

10) K. Yokota and K. Ebato: Bull. Japan Inst. Metals, 10 (1971), 226.

11) G. Krauss, Jr. and B. L. Averbach: Trans. ASM, 52 (1960), 434.

12) N. Yukawa, M. Mizutani and H. Saka: J. Japan Inst. Metals, 31 (1967), 846, 850 \& 855.

13) T. Furukawa: J. Japan Inst. Metals, 32 (1968), 105.

14) H. Kamide and H. Sugawara: J. Japan Inst. Metals, 40 (1976), 1243.

15) M. Kowaka: Bull. Japan Inst. Metals, 17 (1978), 657.

16) T. Okada et al.: Corrosion and Protection Engineering of Materials (Zairyo no Fushoku to Boshoku no Kogaku), ed. by The Soc. Mat. Sci., Japan, Kyoto, (1969), 65.

* Published in Journal of The Society of Materials Science, Japan, 29 (1980), 499, in Japanese, after contributing to this journal. 